\title{
Detecting Endogenous Growth Regulators on the Sarcotesta, Sclerotesta, Endosperm, and Embryo by Paper Chromatography on Fresh and Old Seeds of Two Papaya Varieties ${ }^{1,2}$
}

\author{
Manuel N. Reyes, Agripino Pérez and José Cuevas ${ }^{3}$ \\ ABSTRACT
}

\begin{abstract}
Sarcotesta, sclerotesta, endosperm and embryo of fresh and old $(0$ and 3 years, respectively) seeds of the P.R. 6-65 and P.R. 8-65 papaya varieties were separately analyzed by paper chromatography to determine the presence of natural growth inhibitor that might be responsible for the reduction in germination of papaya seeds during storage.

The results showed that in the innermost seed parts (embryo and endosperm) endogenous growth promoters were found while the outermost structures (sarcotesta and sclerotesta) contained inhibitors. Therefore, it is possible that the natural growth inhibitors of this seed might be minimized by removing the sarcotesta (the gelatinous envelope) of the seed, which contains the most endogenous growth inhibitors, plus a careful washing to eliminate the soluble inhibitors of the sclerotesta during the extraction of seeds from the fruits.
\end{abstract}

\section{INTRODUCTION}

Germination inhibitors have been reported in seeds of many plant species by several authors $(1,2,5,6,7,8,9,11,14,15,16,17,19,20,21)$. They suggest that the substances that inhibit growth may be distributed broadly among the seed parts and that they may affect in different ways the growth processes of the seed.

Bradbeer (3) found that dormancy in the Corylus avellana seed is induced by growth inhibitors originated in the testa. Lippe and Crane (11) found that seed of Prunus persica contain a growth inhibitor, in the inner and outer integuments, that is eliminated when these seed parts are removed.

Miyamoto et al. (13) found a growth inhibitor in the external structures of the seeds of Triticum vulgare.

Luckwill (12) reported that dormancy in apple seeds is due to the presence of growth inhibitors in the seminal structures of the seed. This same author found that the proportion of the inhibitor in the endosperm, testa and embroy is $30: 13: 1$, respectively, and that during storage the only seed part that does not lose its inhibitor is the testa.

${ }^{1}$ Manuscript submitted to Editorial Board January 8, 1979.

${ }^{2}$ Part of a thesis submitted to the Graduate School in partial fulfillment of the requirements for the Master of Science in Horticulture.

${ }^{3}$ Graduate Student; Horticulturist and Associate Professor in Agronomy, respectively, Agricultural Experiment Station: College of Agricultural Sciences, Mayagüez Campus, University of Puerto Rico, Mayagüez and Río Piedras, P. R. 
Lange (10) has suggested the presence of natural growth inhibitors in any of the seminal structures of papaya seeds, and Cairns (4) isolated a compound that he called caricacin, which has a stronger inhibition on the elongation of Phaseolus aureus seedlings. However, Cairns stated that this compound is not a natural growth inhibitor and that it probably appeared as a result of the methods he used in his research.

Papaya plants are usually started from seeds of the ripe fruits that are dried prior to planting. Fresh seeds can germinate within 2 weeks if they are properly handled. There is some evidence (10) suggesting that if the gelatinous envelope (sarcotesta) surrounding the seed is removed, germination is hastened.

Seeds not to be sown immediately were kept in cool storage. However, cool storage affects germination adversely.

This research investigated the problem of seed germination by determining the presence of endogenous growth inhibiting substances in the seminal structure of fresh and old seeds of two papaya varieties.

\section{MATERIALS AND METHODS}

Recently harvested (0 years) and old (3 years) seeds of the P.R. 6-65 and P.R. 8-65 papaya varieties were used for these studies. The 0-yearold seed received no storage, whereas the 3-year-old seeds had been kept in a cold storage room at the Isabela Agricultural Experiment Substation at a temperature of $10 \pm 5^{\circ} \mathrm{C}$ and a relative humidity of $40 \%$.

\section{SEED EXTRACTS}

One hundred seeds of each variety and age were soaked in $20 \mathrm{~cm}^{3}$ of distilled water during 2 hours; then the sarcotesta was removed by squeezing gently each seed against the table with a No. 10 rubber stopper. At this stage the seeds were washed in $30 \mathrm{~cm}^{3}$ of a $4: 1$ methanol:water solution.

The seeds without a sarcotesta were washed several times to eliminate all the mucilagenous sarcotesta, and every single seed was opened with a scalpel to obtain separately the four seminal structures (sarcotesta, esclerotesta, endosperm and embryo) as in figure 1.

The dry material of the sarcotesta and the sclerotesta were ground in a semimicro-Wiley mill fitted with a stainless steel sample funnel and a 20-mesh stainless steel screen. The endosperms and embryos were manually ground separately with a hand homogenizer.

Each seed structure was transferred to a 4:1 methanol:water solution and stored for 18 hours at $0^{\circ} \mathrm{C}$.

After storage, the samples were filtered through a Whatman No. 1 filter paper. The residues were washed three times with a 4:1 methanol: water solution. The filtered extracts were vacuum dried with a low 
pressure pump and stored at $0^{\circ} \mathrm{C}$ in labeled bottles for use in paper chromatography separation.

\section{PAPER CHROMATOGRAPHY AND BIOASSAYS}

The vacuum dried samples as previously prepared were dissolved in 2 $\mathrm{cm}^{3}$ of methanol. One $\mathrm{cm}^{3}$ of it was transferred to a $3 \mathrm{~cm}$ width band of Whatman No. 3 chromatographic paper.

The chromatograms were developed with a 10:1:1 isopropanol, ammonia, water solution, respectively. The Rf distance was $20 \mathrm{~cm}$.

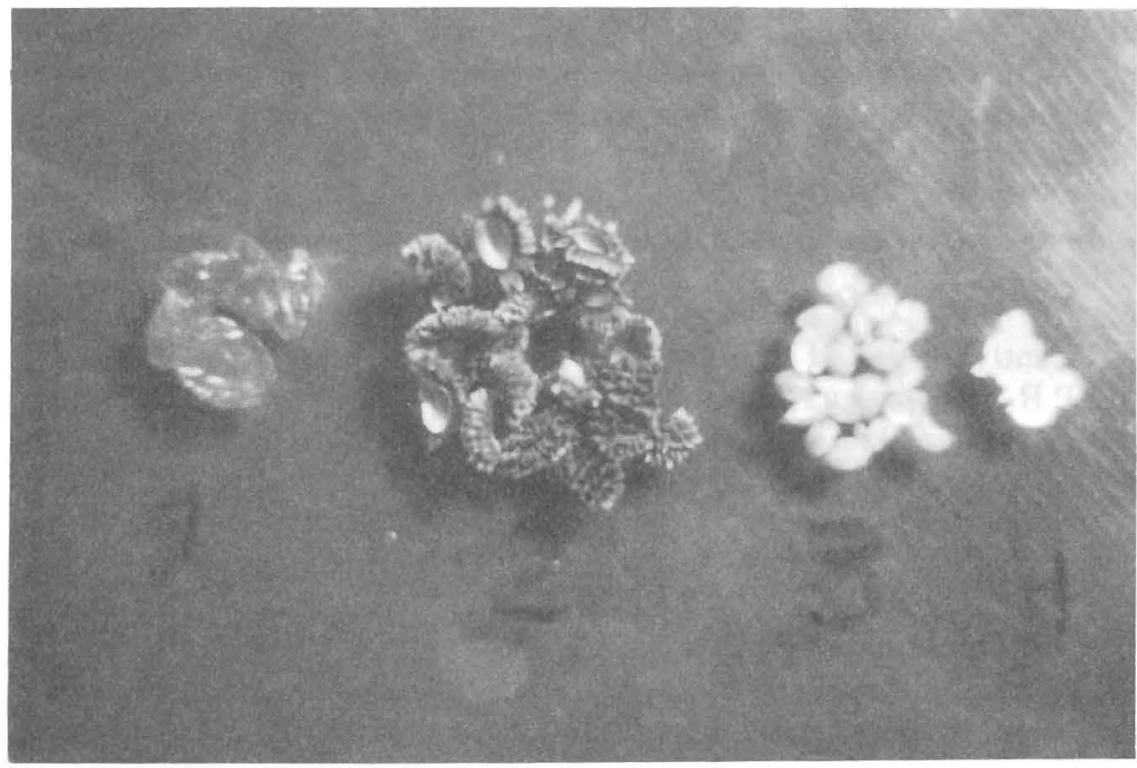

Fig. 1.-Seminal structures of the Carica papaya seeds. From left to right: Sarcotesta, sclerotesta, endosperm and embryo.

The entire chromatogram was cut in 10 sections and each section was placed in a $6 \mathrm{~cm}$-diameter by $1 \mathrm{~cm}$-deep non-sterilized aluminum dish where three seeds of Cucumis sativus were germinated at $35^{\circ} \mathrm{C}$.

At the 28th hour the root lengths of $C$. sativus were measured. The data were analyzed as an $11 \times 2 \times 2$ factorial experiment since a blank chromatogram was used as check. Treatments were replicated three times.

\section{TWO BIOASSAYS UNDER STERILIZED CONDITIONS}

The purpose of these two experiments was to germinate $C$. sativus and C. papaya under the effect of extracts from the four seminal structures of the papaya seeds shown in figure 1 . 
The amount of each extract used from each structure was equal to that used in the previous experiment. The two plant species were germinated in completely sterilized petri dishes containing humid Whatman No. 1 filter paper plus the entire chromatogram. The sclerotesta was entirely removed by hand from the papaya seeds to be germinated prior to treatments.

Years

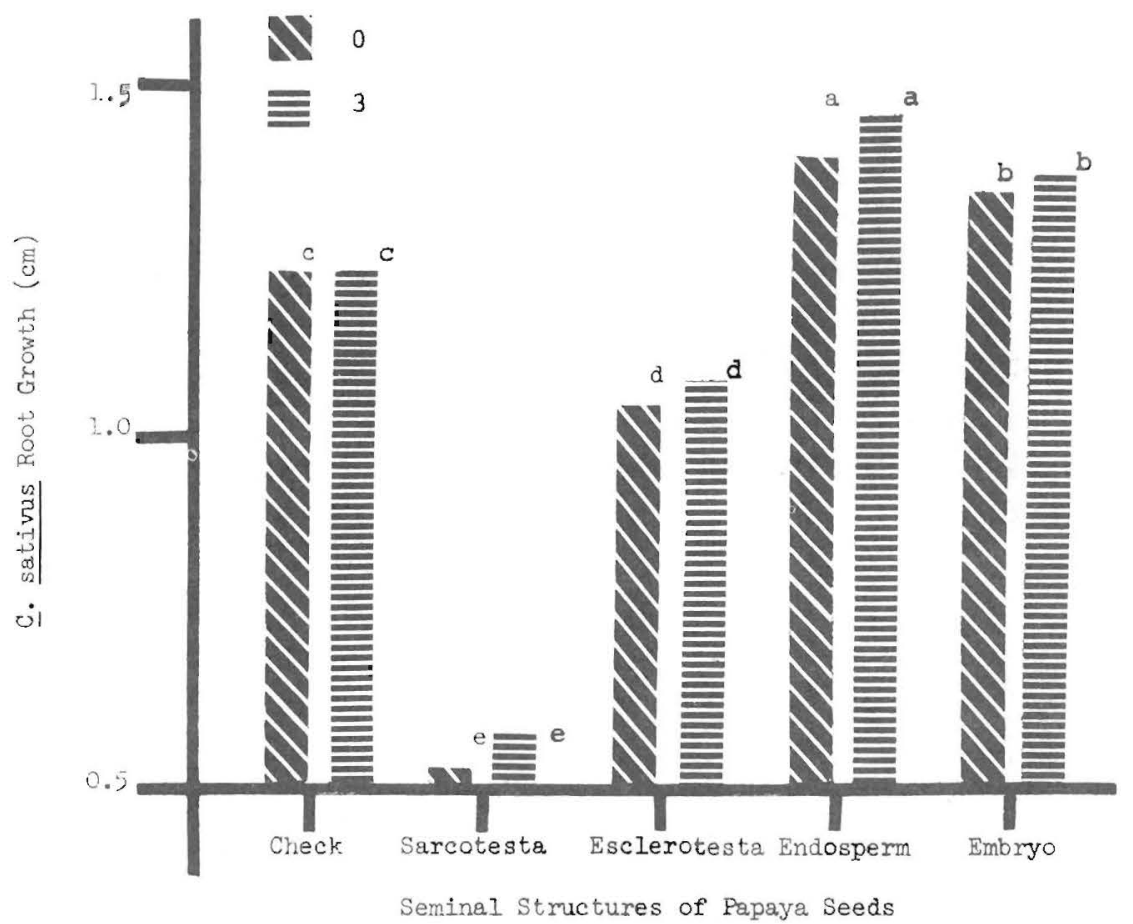

FIG. 2.-Root growth of C. sativus seeds that were germinated in extracts of the entire chromatograms of the sarcotesta, sclerotesta, endosperm and embryo of 0-and 3-year-old papaya seed. The check is referred to the solvent used in the chromotogram. Means followed by one or more letters in common do not differ significantly at the 0.01 level.

The effect of these four seminal structures was measured on the germination of $C$. sativus and C. papaya at 28 hours and at 7 days after treatment, respectively.

The experimental design for each experiment was a $4 \times 2 \times 2$ factorial for the four seed parts, two seed ages and two papaya varieties.

\section{RESULTS AND DISCUSSIONS}

Figures 2, 3 and 4 show that in the 0 - and 3-year-old seeds of the P.R. 6-65 and P.R. 8-65 varieties, the sarcotesta and sclerotesta which are, 
respectively, the two outermost seed covers, contained inhibitors which curtailed the growth of $C$. sativus roots, whereas the innermost seed structures (endosperm and embryo) contained growth promoters. This promotion was greater in the endosperm.

Figure 5 shows that the length of the radicles in the germinating $C$. sativus seeds tends to increase in the $\operatorname{Rf} 5,6,9$ and 10 , which coincides
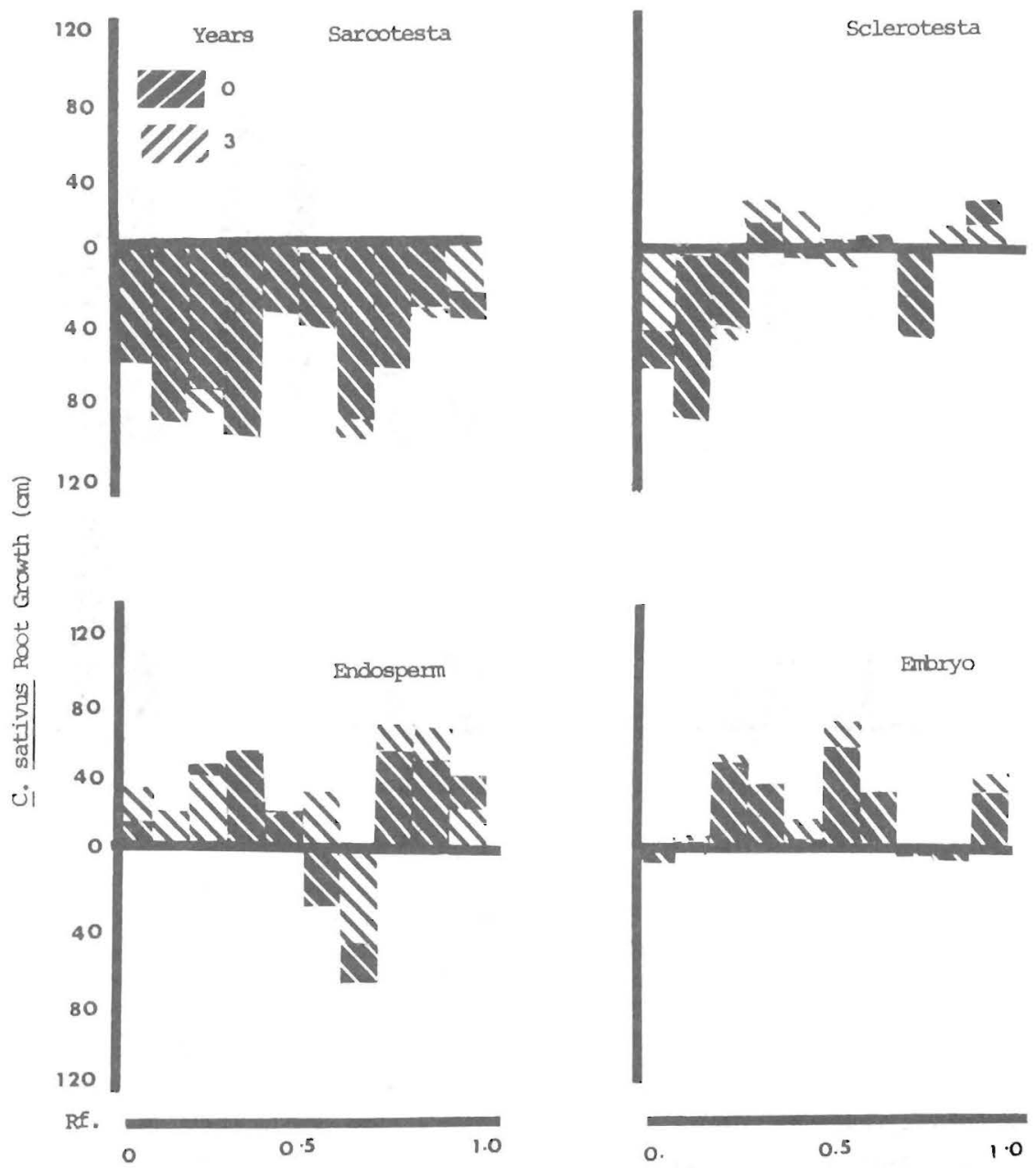

Fig. 3.- Root growth of $C$. sativus germinated in the extracts of 10 fractions of the chromatograms of sarcotesta, sclerotesta, endosperm and embryo of 0 and 3-year-old seeds of the P.R. 6-65 papaya variety. 

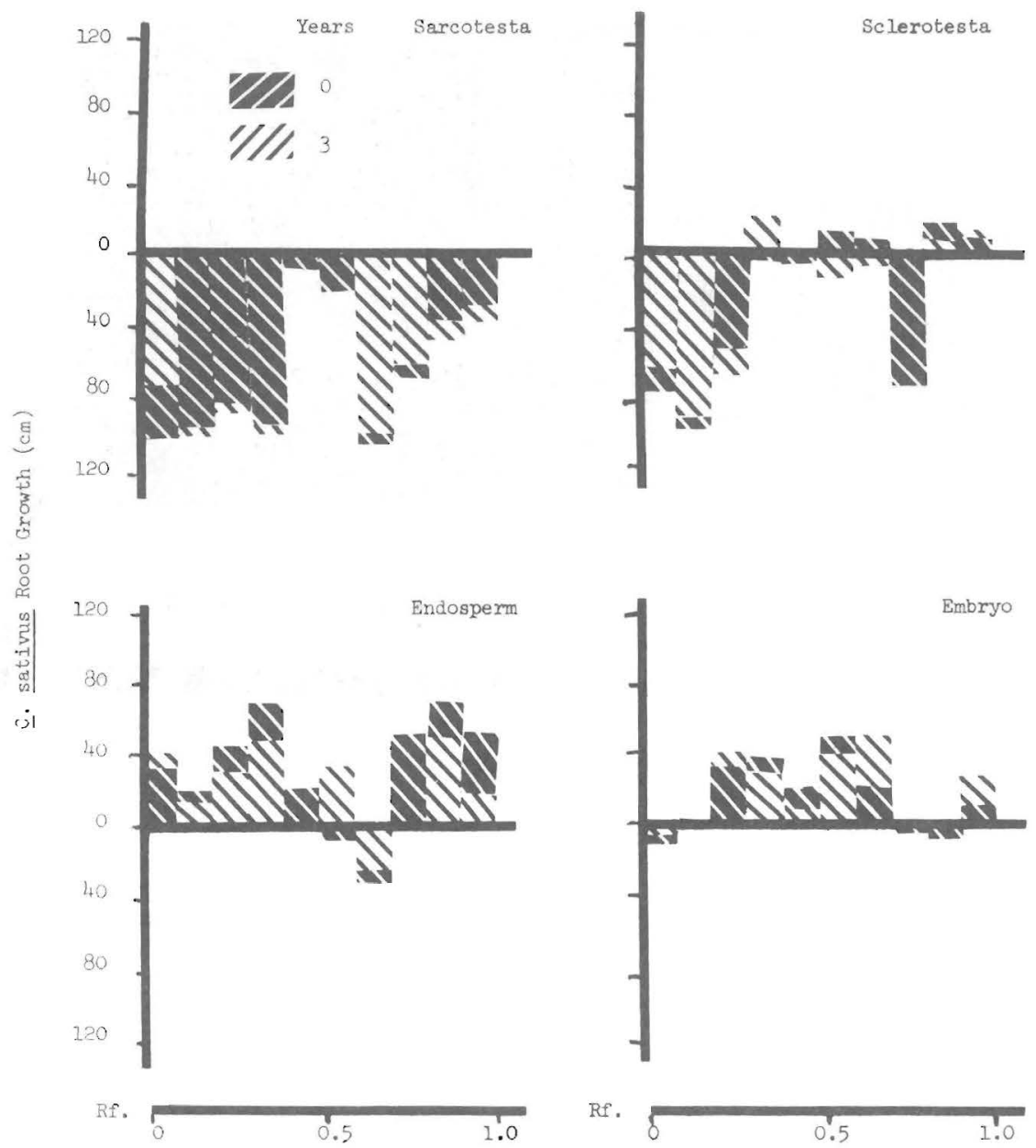

Fig. 4.-Root growth of $C$. sativus germinated in the extracts of 10 fractions of the chromatograms of sarcotesta, sclerotesta, endosperm and embryo of 0 and 3-year-old seeds of the P.R. 8-65 papaya variety.

with the low inhibiton of growth for these same fractions as shown in the sarcotesta on figures 3 and 4 for the two varieties, respectively.

The germination of $C$. sativus and $C$. papaya was significantly promoted by extracts of the embryo and endosperm, and inhibited by extracts from the sclerotesta and sarcotesta as shown in table 1 and fixure 6.

These findings confirm the resutts of Lange (10), who insinuated that 


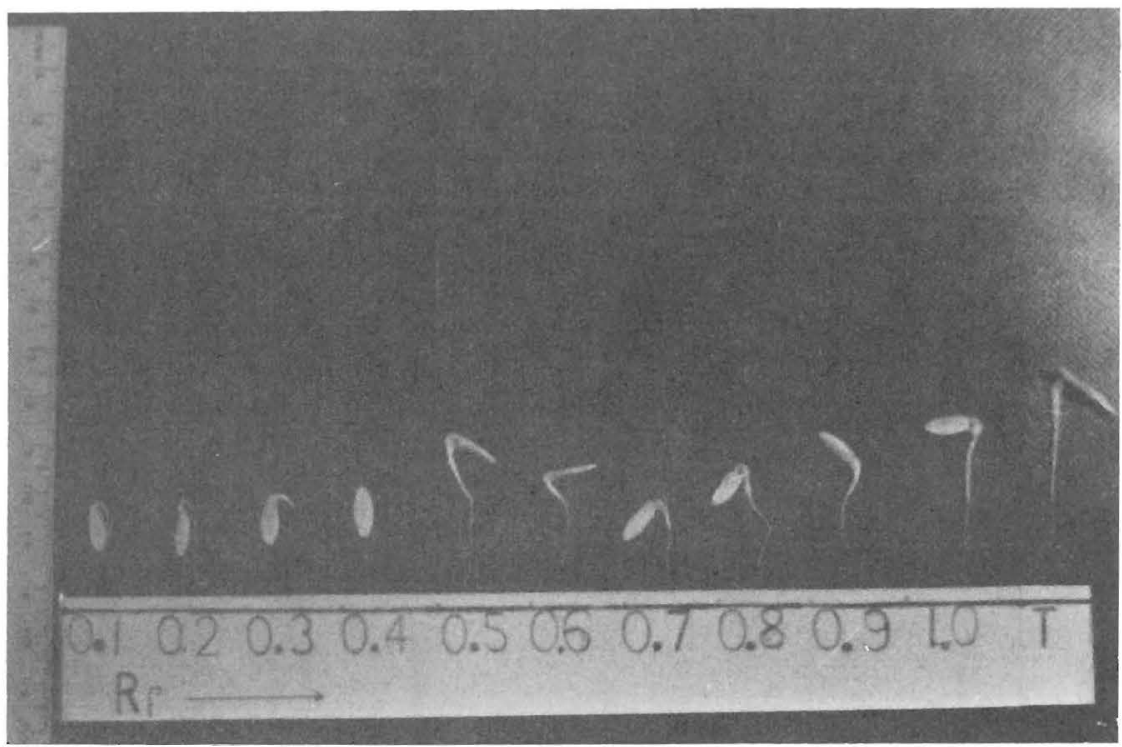

FIG. 5.-Effect of each Rf fraction from the sarcotesta of fresh P.R. 8-65 papaya seeds on the root elongation of germinating seeds of Cucumis sativus.

TABLE 1.-Germination percentage of C. papaya and C. sativus seeds treated with all the extracts in the entire chromatogram of the sarcotesta, sclerotesta, endosperm and embryo of 0 and 3-year-old seeds of the P.R. 6-65 and P.R. 8-65 papaya varieties.

\begin{tabular}{|c|c|c|c|c|c|c|c|c|}
\hline \multirow{4}{*}{ Germination } & \multicolumn{8}{|c|}{ Seminal structures } \\
\hline & \multicolumn{2}{|c|}{ Sarcotesta } & \multicolumn{2}{|c|}{ Sclerotesta } & \multicolumn{2}{|c|}{ Endosperm } & \multicolumn{2}{|c|}{ Embryo } \\
\hline & \multicolumn{8}{|c|}{ Seed age (yr) } \\
\hline & 0 & 3 & 0 & 3 & 0 & 3 & 0 & 3 \\
\hline & $\%$ & $\%$ & $\%$ & $\%$ & $\%$ & $\%$ & $\%$ & $\%$ \\
\hline & \multicolumn{8}{|c|}{ P.R. 6-65 } \\
\hline C. papaya & $20 d^{1}$ & $30 \mathrm{~d}$ & $70 \mathrm{c}$ & $75 b c$ & $75 \mathrm{bc}$ & $100 \mathrm{ab}$ & $90 \mathrm{ab}$ & $95 a b$ \\
\hline \multirow[t]{2}{*}{ C. sativus } & $17 \mathrm{~d}$ & $20 \mathrm{~d}$ & $37 \mathrm{~cd}$ & $43 b c$ & $63 a b$ & $67 a$ & $77 a$ & $7 \%$ \\
\hline & \multicolumn{8}{|c|}{ P.R. 8-65 } \\
\hline C. papaya & $15 \mathrm{~d}$ & $25 \mathrm{~d}$ & $65 c$ & $85 b$ & $100 \mathrm{ab}$ & $100 \mathrm{ab}$ & $85 b$ & $100 a b$ \\
\hline C. sativus & $17 \mathrm{c}$ & $20 \mathrm{c}$ & $47 \mathrm{~b}$ & $43 \mathrm{~b}$ & $67 a$ & $67 a$ & $63 \mathrm{ab}$ & $60 \mathrm{ab}$ \\
\hline
\end{tabular}

${ }^{1}$ Mean values in the same rows followed by one or more letters in common do not differ significantly at the 0.05 probability level.

some growth inhibitors may be found in the outer seminal structures of the papaya seed because he hastened and increased papaya seed germination by removing the sarcotesta. They also suggest that endogenous growth inhibitors arising in the outermost seed coats of the papaya seeds 


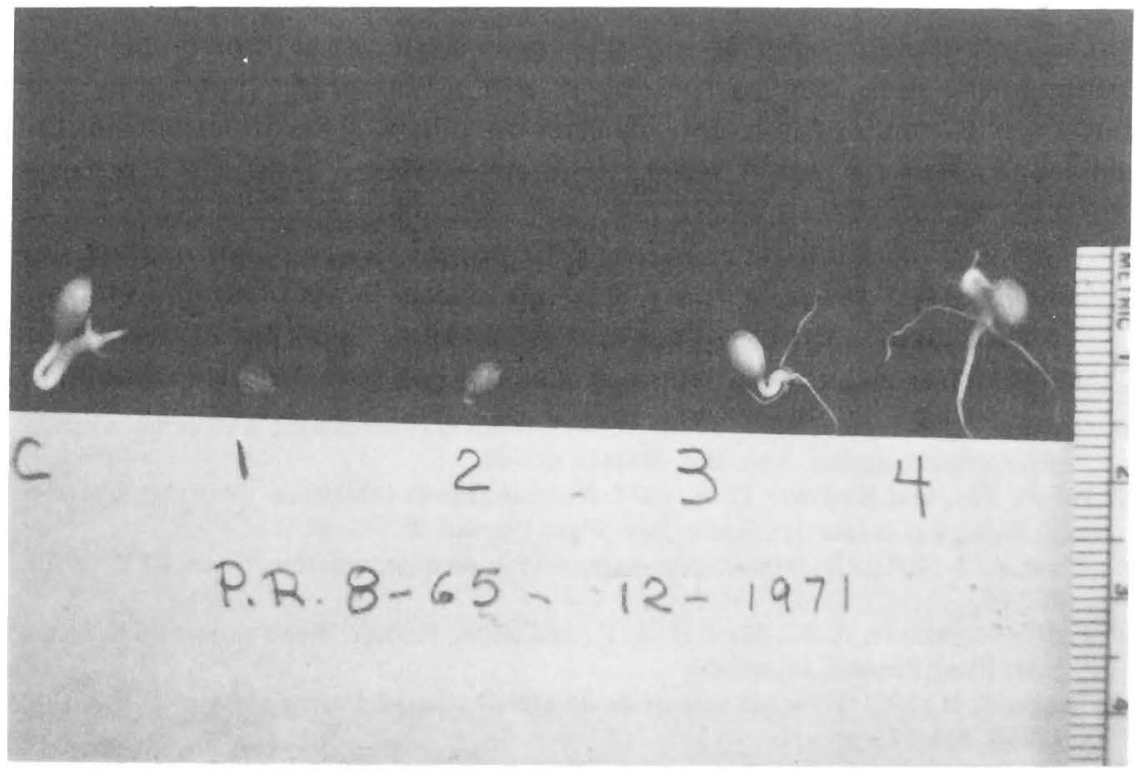

FIG. 6.-Effect of extracts from the check (c) Sarcotesta, sclerotesta, endosperm and embryo on the germination of P.R. 8-65 papaya variety seeds to which the sclerotesta was removed before treatment.

might be minimized by removal of the sarcotesta and careful washing of the seeds.

\section{RESUMEN}

Las cuatro estructuras seminales (sarcotesta, esclerotesta, endosperma y embrión) de semilla recién cosechada y vieja (0 y 3 años, respectivamente) de las variedades de papaya P.R. 6-65 y P.R. 8-65 fueron analizadas separadamente usando chromatografía de papel. El propósito de este estudio era determinar la presencia de inhibidores endógenos del crecimiento en estas envolturas seminales que pudieran ser responsables de la reducción de viabilidad de la semilla de papaya durante el almacenamiento.

Los resultados demostraron que en las envolturas externas (sarcotesta y esclerotesta) de la semilla recién cosechada y vieja de las dos variedades se encuentran inhibidores naturales del crecimiento, mientras que en las internas (embrión y endosperma) están los que lo activan. Por lo tanto, es posible que los inhibidores pudieran reducirse considerablemente si se elimina la sarcotesta que es el arilo mucilaginoso que envuelve la semilla y que es el que mayor cantidad de inhibidores contiene, y también, las semillas se lavan bien al extraerlas de la fruta. 


\section{LITERATURE CITED}

1. Amen, R. D., 1968. A model of seed dormancy, Bot. Rev. 34(1): 1-31.

2. Ballard, L. A. T. and Lipp, A. E., 1959. Differential specifity exhibited by two germination inhibitors present in Echium platagineum L., Can. J. Bot. 37(3): 343-47.

3. Bradebeen, J. W., 1968. Studies in seed dormancy. IV. The role of endogenous inhibitors and gibberellin in the dormancy and germination of Corylus avellana L. seed. Planta 78(3): $266-76$.

4. Cairns, T. M., 1968. Isolation and identification of caricacin, a plant growth inhibitor in the metanolic extract of Carica papaya L. Ph.D. Thesis, Univ. Calif. Riverside, 63 pp.

5. Everani, M., 1949. Germination inhibitors. Bot. Rev. 15(3): 153-94.

6. Goodchild, N. A. and Walker, M. G. A., 1971. Method of measuring seed germination in physiological studies, Ann. Bot. 35(141): 615-21.

7. Kefeli, V. I. and Kadyrov, C. S., 1971. Natural growth inhibitors, their chemical and physiological properties, Annu. Rev. Plant Physiol. 22:185-96.

8. Khan, A. A., 1971. Cytokinins; permissive role in seed germination, Science 171 (3974): 853-58.

9. Koller, D., Mayer, A. M., Mayber, A. P., and Klein, S., 1962. Seed germination, Annu. Rev. Plant Physiol. 13: 437-57.

10. Lange, A. H., 1961. Effect of sarcotesta on germination of Carica papaya L., Bot. Caz. 122(4): 305-11.

11. Lipe, W. N. and Crane, J. C., 1966. Dormancy regulation in peach seed, Science 153(3735): 541-42.

12. Luckwill, L. C., 1952. Growth-inhibiting and growth-promoting substances in relation to the dormancy and after-ripening of apple seeds, J. Hort. Sci. 59:53-67.

13. Miyamoto, T., Tolbert, N. E., and Everson, E. H., 1961. Germination inhibitors related to dormancy in wheat seed, Plant Physiol. 36(6): 739-46.

14. Nikkelsen, D. S. and Sinah, M. S., 1961. Germination inhibition in Oryza sativa and control by preplanting soaking treatment, Crop. Sci. 1(5): 332-35.

15. Sen, D. N. and Chawan, D. D., 1970. Ecology of desert plants and observations on their seedling. III. The influence of aqueous extracts of Prosopis juliflora DC on Euphorbia caducifolia Haines. Vegetation 21 (4-6): 271-98.

16. Soriano, A. R., Sánchez, A., and de Eilberg, B. A., 1964. Factors and processes in the germination of Datura ferox L., Can J. Bot. 42(9): 1189-1203.

17. Toole, E.. H., Hendricks, S. B., Borthwick, H. A., and Toole, V. K., 1956. Physiology of seed germination, Annu. Rev. Plant Physiol. 7; 299-319.

18. - Toole, V. K., Borthwick, H. A. and Hendricks, S. B., 1955. Photocontrol of Lepidium seed germination, Plant Physiol. 30(1): 15-21.

19. Villers, T. A. and Wareing, P. F., 1965. The growth-substance content of dormant fruits of Froxinus excelsior L. J. Exp. Bot. 16(48): 533-44.

20. Wareing, P. R. and Foda, H. A., 1957. Growth inhibitors and dormancy in Xanthium sp. seed, Physiol. Plant. 10(2): 266-80.

21. - and Saunders, P. F., 1971. Hormones and dormancy, Annu. Rev. Plant Physiol. 22: $261-81$. 